\title{
Bipolar Disorder and Tuberous Sclerosis Complex: Is It A Mere Coincidence?
}

\section{To the Editor:}

Tuberous sclerosis complex (TSC) is associated with significant psychiatric comorbidity mainly in the form of autistic disorders, hyperkinetic disorders, depression, and anxiety disorders. There are very few reports of bipolar disorder in TSC.

The authors present the case of a patient with TSC having bipolar disorder manifesting as manic as well as depressive episodes. The diagnosis of TSC was based on the presence of facial angiofibromas, enamel pits, and shagreen patches on clinical examination, and the presence of cortical tubers and calcified subependymal nodules on neuroimaging. The patient presented during the manic phase of the illness and responded well to treatment with carbamazepine and haloperidol and became symptom free within 1 month. The patient's neuropsychological assessment revealed a borderline level of intellectual functioning and deficits in attention and concentration, recent memory, delayed and immediate recall, and visual retention.

To our knowledge, this is the first report of TSC with bipolar disorder having both manic as well as depressive episodes. The nature of association between TSC and bipolar disorder, and its clinical implications are discussed.

\section{INTRODUCTION}

TSC, the second most common neurocutaneous syndrome after neurofibromatosis type 1, although first described by Von Recklinghausen, ${ }^{1}$ was comprehensively described by Bourneville ${ }^{2}$ who coined the term sclerose tubereuse. TSC is transmitted in an autosomal dominant manner with complete penetrance and variable expression, resulting from mutations in one of the two genes-TSC1 gene encoding hamartin located on chromosome $9 \mathrm{q}^{3} 4^{3}$ and TSC2 gene encoding tuberin located on chromosome $16 p 13 .{ }^{4}$ The disinhibition of the Mammalian Target of Rapamycin pathway due to abnormal tuberin or hamartin resulting from these mutations leads to deregula- tion in organogenesis and consequent tumors, which may affect any organ in the body especially brain, skin, kidneys, heart, eyes, and lungs.'

Initially considered a rare disorder, TSC is now known to occur in around 1 in 6,000 live births. ${ }^{5}$ The revised criteria for diagnosis require the presence of two major or one major and two minor features for a definitive diagnosis of TSC. Among the major features are facial angiofibromas, periungual fibroma, hypomelanotic macules, shagreen patch, cortical tuber, and subependymal nodule; while multiple enamel pits, hamartomatous rectal polyps, bone cysts, cerebral white-matter migration tracts, and gingival fibromas are among the minor features. Around $50 \%$ to $70 \%$ patients have been attributed to new mutations. The $15 \%$ to $20 \%$ false negative rate for DNA testing and the presence of somatic and germline mosaicism renders DNA testing at present, only to complement the clinical diagnosis and assist in genetic counseling. ${ }^{2}$

TSC is associated with significant psychiatric comorbidities. The prevalence of psychiatric comorbidities reported in TSC, although variable, ranges from $19 \%$ to $43 \%$ for depressive disorders, $5 \%$ to $56 \%$ for anxiety disorders, $26 \%$ to $86 \%$ for ADHD, $13 \%$ to $56 \%$ for aggressive and disruptive behaviors, and $21 \%$ for autistic like conditions. ${ }^{6.7}$ Other comorbidities reported less frequently include schizophrenia, Capgras' syndrome, psychosis, auditory hallucinations, anorexia nervosa, alcoholism, and expressive language disorder. ${ }^{7}$ Although the prevalence of comorbid depressive disorders in TSC is reported to be quite high, a Pubmed, Sciencedirect, and IndMED search carried until August 2008 revealed only four reports of comorbid mania/bipolar disorder in TSC, with three of them having only manic episodes, ${ }^{8,9,10}$ while the details of the fourth are not available. ${ }^{11}$ We report the first patient of TSC with comorbid bipolar affective disorder having manic as well as depressive episodes to discuss the nature of association between the two and its clinical implications. 


\section{CASE REPORT}

Mrs. A.D., a 26 year old married female, educated up to $12^{\text {th }}$ standard, having a normal birth and developmental history, and a well balanced premorbid personality was brought by her guardians to the adult psychiatry outpatient department of Central Institute of Psychiatry (Ranchi, India; a tertiary referral treatment center) in April 2008 with 3 months history of an acute onset illness characterized by talking excessively, making grandiose plans, wandering and meeting people to pursue her plans, and demanding and abusive behavior when her demands were not met. She would not feel the need to sleep as before and her mood would fluctuate from irritability to elation. There was no history of any psychiatric or neurological illness in the patient's family.

Exploring the patient's past revealed some interesting psychiatric and neurological facets. At 5 years of age, the patient had started having complex partial seizures progressing to generalized tonic clonic seizures that were treated successfully with carbamazepine $200 \mathrm{mg} / \mathrm{day}$. After $\sim 7$ years, the patient stopped taking carbamazepine without any further recurrence of seizures and was maintaining well until May 2004, when she started talking less, staying aloof, having decreased interest in work, low mood, and decreased sleep, and gradually started exhib-

\section{Figure 1. \\ Angiofibromas over the face (Adenoma Sebaceum)}

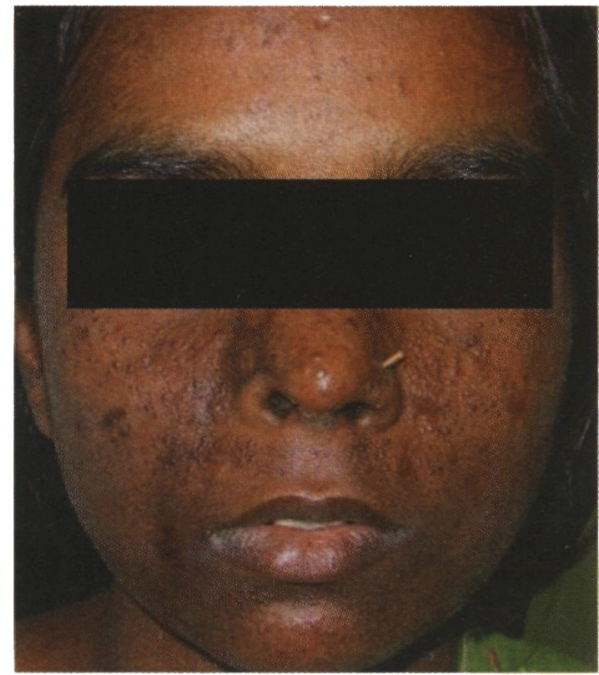

Haq MZU, Dubey I, Khess CRJ, Das U, Kumar R. CNS Spectr. Vol 14. No 11. 2009 iting hallucinatory behavior. Inquiry revealed the hallucinations to be auditory in nature consisting of derogatory remarks addressed to the patient in second person. The symptoms lasted for $\sim 4$ months and were treated successfully with olanzapine $15 \mathrm{mg} /$ day which the patient stopped taking by December 2004. The patient maintained well until December 2006, when she had a similar episode lasting $\sim 2$ months which was again treated with olanzapine $10 \mathrm{mg} /$ day. Both episodes qualified for a diagnosis of severe depressive episode with psychotic symptoms. ${ }^{12}$ The patient stopped taking olanzapine by May 2007 and remained well until the present episode. The patient's physical examination revealed angiofibromas over face (Figure 1), multiple small enamel pits, and shagreen patches over the lumbosacral area (Figure 2).

The mental status examination revealed a young female who was talking excessively with decreased reaction time, inflated self esteem and delusion of grandiosity, having a poor insight into her illness. On the basis of the current nosological systems patient was diagnosed as organic bipolar disorder with TSC.,12 The patient was started on carbamazepine and haloperidol which were gradually increased to $400 \mathrm{mg} /$ day and $10 \mathrm{mg} /$ day, respectively. In the mean time, the patient was thoroughly investigated to look for the stigmata of TSC. All routine investigations such as hemogram, liver and kidney function tests, electrocardiography, and electroencephalography (EEG) were normal. X-ray of the hands revealed irregu-

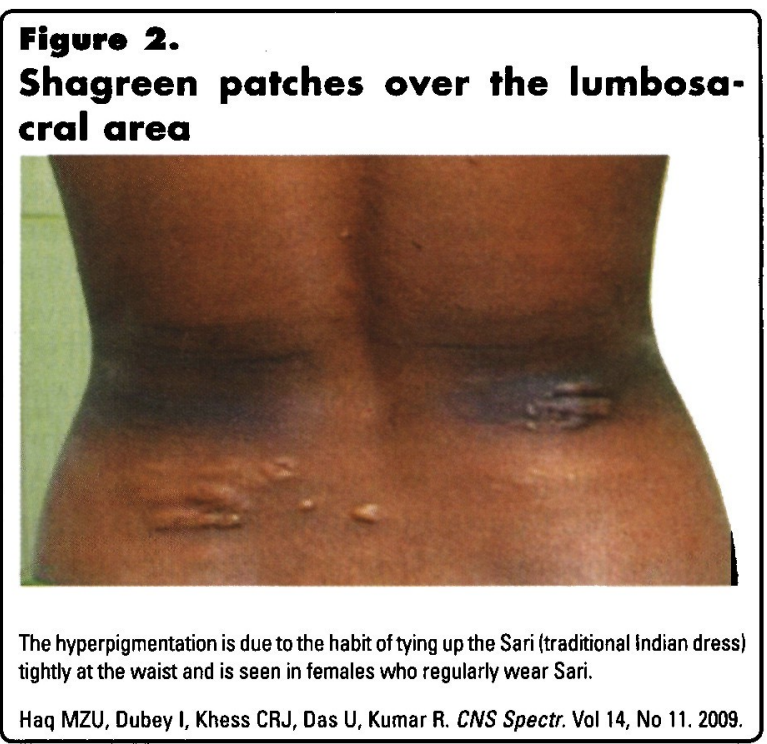


lar cortical thickening of phalanges bilaterally, predominantly the proximal phalanges (Figure 3). Computed tomography (CT) scan of the head revealed irregular thickening of the calvarium (Figure 4), multiple calcified subependymal nodules (Figure 5), a thickened gyrus (cortical tuber) in the right frontal region (Figure 6), and multiple subcortical white matter hypodense lesions (Figures 5 and 6). There was no enhancement of any of these lesions with contrast. Plain as well as contrast CT scan of the thorax and abdomen did not reveal any abnormality.

The patient showed good response to the combination of carbamazepine and haloperidol with complete resolution of the symptoms within 1 month. As the patient became asymptomatic, her intelligence quotient and neuropsychological functions were assessed. On standard IO tests, patient had an 10 of 79 (verbal quotient of 72.5 and performance quotient of 85.5 ) indicating a borderline level of intellectual functioning. Neuropsychological assessment using Post Graduate Institute-Battery of Brain Dysfunction ${ }^{13}$ revealed significant deficits in attention and concentration, and moderate level of dysfunction in recent memory, delayed and immediate recall, and visual retention. The patient showed an intact visuo-perceptual acuity, depth perception, ability

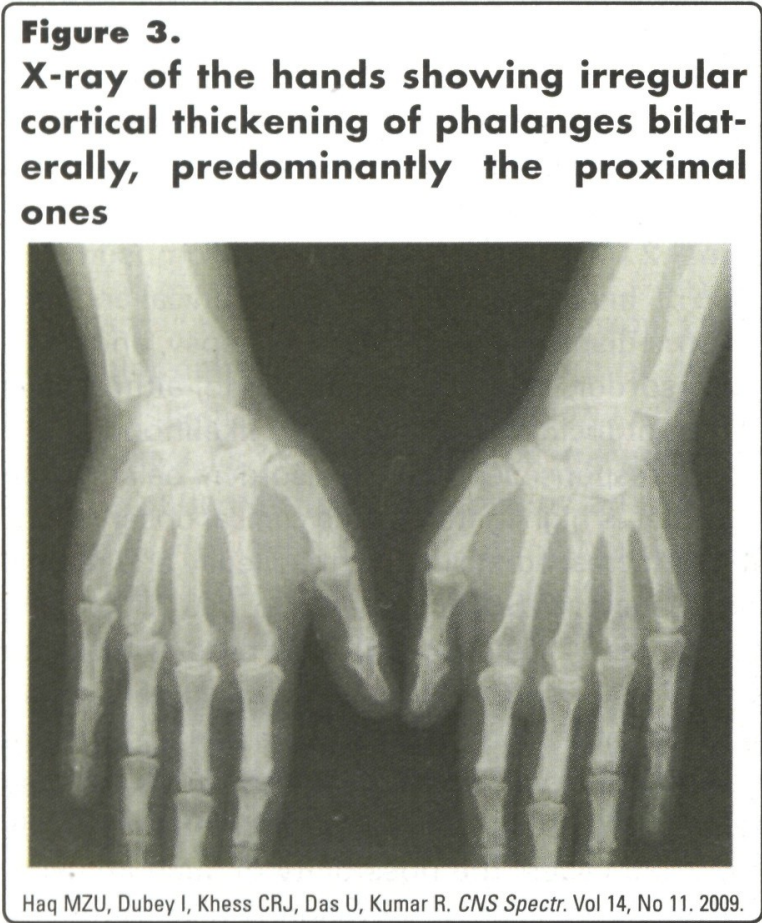

to appreciate spatial relationships, remote memory, and ability to respond correctly when cues are available. ${ }^{13}$ The patient was discharged from

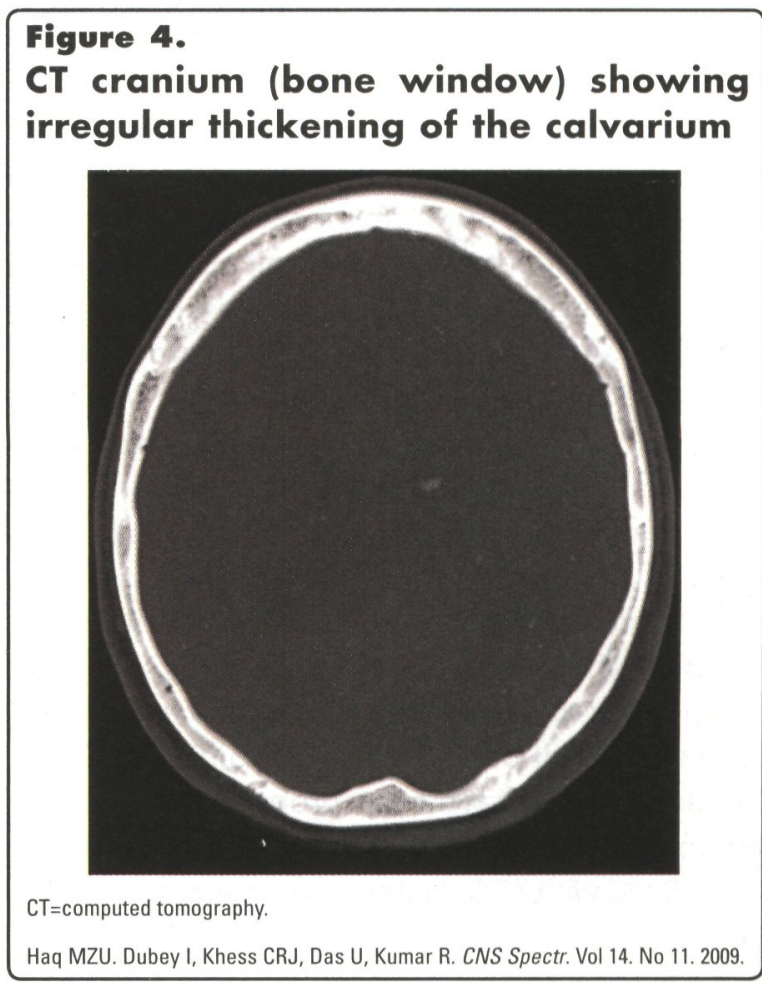

Figure 5.

Plain CT brain scan showing multiple calcified subependymal nodules and subcortical hypodensities

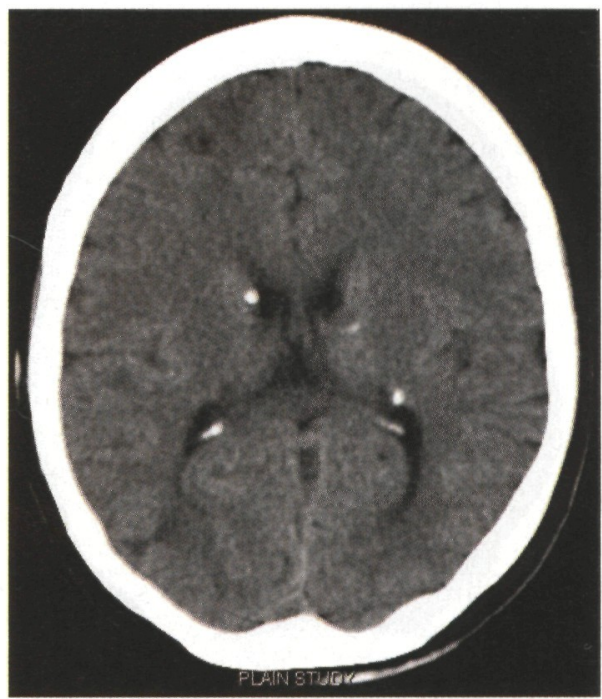

$\mathrm{CT}=$ computed tomography.

Haq MZU. Dubey I, Khess CRJ, Das U, Kumar R. CNS Spectr. Vol 14. No 11. 2009. 
the hospital after receiving appropriate genetic counseling and was maintaining well on followups for the next 5 months.

\section{DISCUSSION}

Bipolar disorder occurring in association with TSC may be attributed to psychosocial stressors, epilepsy, and use of anticonvulsant drugs (ACDs) associated with TSC or may be a chance association. ${ }^{11}$ Our patient was quite well adjusted, married, and performing her social role as a home maker adequately, like most other women in her village. She was not bothered by the disfiguring angiofibromas over her face and had never sought any treatment for these. Considering the apparent lack of any significant psychosocial impairment due to TSC in our patient, psychosocial stress seems to be an unlikely contributor to her bipolar illness.

Epilepsy and the use of ACDs are associated with significant psychiatric comorbidity including bipolarity, ${ }^{14}$ and have been proposed as possible etiological mechanisms for psychiatric disorders associated with TSC. ${ }^{11}$ Interestingly, our patient had seizures for only a short duration around 5 years of age and had stopped taking carbamazepine for

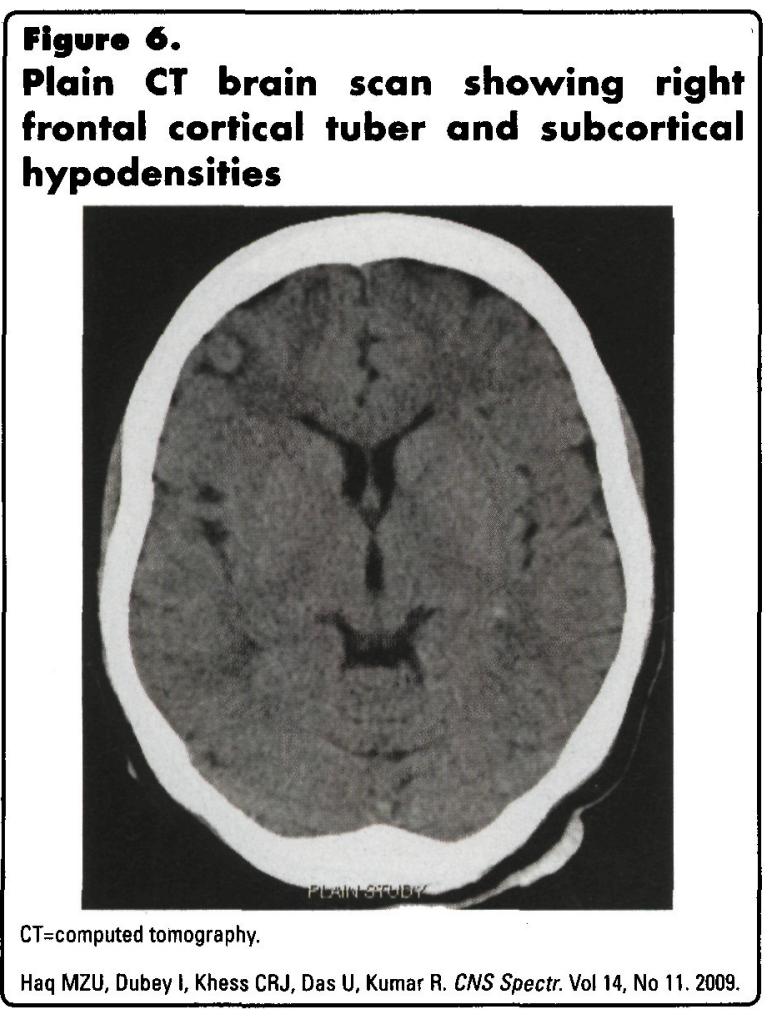

over 10 years before the first episode of depression, making these as untenable causal mechanisms. Taking this into consideration, we propose the brain lesions in TSC as the etiology behind the bipolar affective disorder rather than any causal association between the two disorders.

The support for our proposition comes from studies of psychiatric comorbidities in patients with brain lesions that are linked more to the site of the lesion than the underlying disorder. ${ }^{15,16}$ Traditionally right hemispheric lesions have been associated with mania more than left hemispheric ones. It has also been found that subcortical lesions are associated with the development of manic as well as depressive episodes, whereas cortical lesions are associated with the development of pure manic episodes. Further, a significant proportion of patients with brain lesions experience episodes of depression prior to the development of secondary mania, which has been proposed to be of pathophysiological significance. ${ }^{16}$ Besides the right frontal cortical tuber, our patient had predominantly subcortical lesions and had experienced two episodes of depression prior to the manic episode, thereby invoking the possibility of these brain lesions as the likely causative mechanism. The earlier reports of bipolarity in TSC support our proposition of association of the two disorders based on the site of the lesion, as evidenced from the EEG reports of those patients showing foci over the right temporal $^{8}$ and right frontotemporal areas ${ }^{10}$ consistent with their presentation as manic episodes only.

Another possible etiological link between TSC and bipolarity seems to be a genetic one. The terminal $2 \mathrm{Mb}$ of the short arm of chromosome 16 (16p13) harbors genes for many medical and psychiatric disorders like autism, epilepsy, and bipolar disorder, beside the TSC2 gene, although at different loci. ${ }^{17,18}$ The increased likelihood of the genes responsible for these disorders being linked together is highlighted by the clinical observations of the increased incidence of epilepsy and mental retardation in TSC 2 compared to TSC $1 .^{7}$ Keeping this in view, the association of bipolar disorder with TSC 2 seems to result from linkage disequilibrium rather than any other causal association between the two. However, in the absence of any genetic studies in our patient and the previously reported cases, the possibility of such an association remains an assumption at best. Although 
there seems to be more than one possible mechanism for the association between TSC and bipolar disorder, a few case reports can not rule out the possibility of a chance association.

Our patient showed a borderline level of intellectual functioning and deficits in attention and concentration, recent memory, delayed and immediate recall, and visual retention which are consistent with the reports from earlier studies. ${ }^{19}$ The apparent lack of intellectual deficits in the history of our patient and the level of her academic achievement can be explained on the basis of her less cognitively demanding social environment and the very low standards of education in the rural community she belongs to. The intellectual disability in TSC has been positively correlated with the severity of epilepsy, especially the infantile spasms and the tuber brain ratio. ${ }^{20}$ Our patient seems atypical in having intellectual disability that seems out of proportion to the few seizures she had. This apparent discrepancy can be explained on the basis of a study by Raznahan and colleagues, ${ }^{21}$ who showed that intellectual disability correlated with frontal and temporal cortical tuber load rather than epilepsy. The presence of a right frontal cortical tuber in our patient seems to be in line with this observation.

\section{CONCLUSION}

Although genetic mutation, seizure history, surgical history and cognitive impairment have been shown to be significantly associated with psychiatric comorbidity in TSC, it seems difficult to predict the likelihood of specific psychiatric comorbidities like bipolarity given the rarity of such cases. ${ }^{7}$ Future studies in neuroimaging and molecular genetics of TSC seem to offer some hope in this direction. Considering the rarity of bipolar disorder in TSC, the clinical management of these patients should be done on an individual basis. However, the use of anticonvulsant mood stabilizers seems obvious because of the very high incidence of epilepsy $(80 \%-90 \%)$ in TSC. ${ }^{2}$ The clinician also needs to be alert to the possibility of a switch while prescribing antidepressants to TSC patients with depression, given the possibility of a bipolar predisposition.

\section{Sincerely,}

Mohammad Zia UI Haq, DPM, Indu Dubey, MPhil, Christoday R. J. Khess, MD, Utpal Das, MD, and Rakesh Kumar, DPM

\section{REFERENCES}

1. Crino PB, Nathanson KL. Henske EP. The tuberous sclerosis complex. N Eng/ J Med 2006:355:1345-1356.

2. Roach ES. Sparagana SP. Diagnosis of tuberous sclerosis complex. $J$ Child Neurol 2004:19:643-649.

3. van Slegtenhorst $M$, De Hoogt $R$, Hermans $C$, et al. Identification of the tuberous sclerosis gene tsc1 on chromosome 9q34. Science. 1997;227:805-808.

4. The European Chromosome 16 Tuberous Sclerosis Consortium. Identification and characterization of the tuberous sclerosis gene on chromosome 16. Cell. 1993;75:1305-1315

5. Osborne JP, Fryer AE, Webb DW. Epidemiology of tuberous sclerosis. Ann NY Acad Sci. 1991;615:125-127.

6. Gillberg IC. Gillberg C. Ahlsen G. Autistic behavior and attention deficits in tuberous sclerosis: a population-based study. Dev Med Child Neurol. 1994;36:50-56.

7. Muzykewicz DA, Newberry P, Danforth N, Halpern EF, Thiele EA. Psychiatric comorbid conditions in a clinic population of 241 patients with tuberous sclerosis complex. Epilepsy Behav. 2007;11:506-513.

8. Khanna R, Borde M. Mania in a five-year-old child with tuberous sclerosis. $B r J$ Psychiatry. 1989:155:117-119.

9. Hagenah U, Coners $\mathrm{H}$, Kotlarek $F$, et al. Tuberous sclerosis and organic bipolar disorder

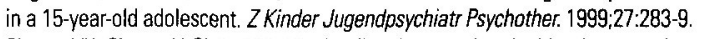

10. Chopra VK, Cintury Y, Sinha VK. Bipolar disorder associated with tuberous sclerosis: chance association or aetiological relationship? Indian J Psychiatry. 2006;48:66-68.

11. Raznahan A, Joinson C, O'Callaghan F, Osborne JP, Bolton PF. Psychopathology in tuberous sclerosis: an overview and findings in a population-based sample of adults with tuberous sclerosis. J Intellect Disabil Res. 2006;50:561-569.

12. World Health Organization. The ICD-10 Classification of Mental and Behaviour Disorders—Clinical Descriptions and Diagnostic Guidelines. Geneva, Switzerland: World Health Organization; 1992.

13. Pershad D, Verma SK. Post Graduate Institute Battery of Brain Dysfunction. Agra, India: National Psychological Corporation; 1990.

14. Das A, Khanna R. Organic manic syndrome: causative factors, phenomenology and immediate outcome. J Affect Disord. 1993;27:147-153.

15. Starkstein SE, Boston JD, Robinson RG. Mechanisms of mania after brain injury: 12 case reports and review of literature. J Nerv Ment Dis. 1988;176:87-100.

16. Starkstein SE, Fedoroff P, Berthier ML, Robinson RG. Manic-Depressive and pure manic states after brain lesions. Biol Psychiatry 1991;29:149-158.

17. Ewald $H$, Flint $T$, Kruse TA, Mors $D$. A genome-wide scan shows significant linkage between bipolar disorder and chromosome $12 q 24.3$ and suggestive linkage to chromosomes 1p22-21, 4p16, 6q14-22, 10q26 and 16p13.3. Mol Psychiatry. 2002;7:734-744.

18. Daniels RJ, Peden JF, Liyod C, et al. Sequence, structure and pathology of the fully annotated terminal $2 \mathrm{Mb}$ of the short arm of human chromosome 16 . Hum $\mathrm{Mol}$ Genet. 2001;10:339-352.

19. Prather $P$, deVries PJ. Behavioural and cognitive aspects of Tuberous Sclerosis (TSC). $\checkmark$ Child Nourol. 2004;19:666-674.

20. Jansen FE, Vincken KL, Algra A, et al. Cognitive impairment in tuberous sclerosis complex is a multifactorial condition. Neurology. 2008;70:916-923.

21. Raznahan A, Higgins NP, Griffiths PD, Humphrey A, Yates JR, Bolton PF. Biological markers of intellectual disability in tuberous sclerosis. Psychol Med. 2007;37:1293-304.

Dr. Haq is a senior resident in the Department of Psychiatry at the Central Institute of Psychiatry in Ranchi, India. Dr. Dubey is assistant professor in the Department of Clinical Psychology at the Central Institute of Psychiatry in Ranchi, India. Dr. Khess is professor of psychiatry in the Department of Psychiatry at the Central Institute of Psychiatry in Ranchi, India. Dr. Das is assistant professor in the Department of Radiology at the Central Institute of Psychiatry in Ranchi, India. Dr. Kumar is a senior resident in the Department of Psychiatry at the Central Institute of Psychiatry in Ranchi, India. Faculty Disclosures: The authors do not have an affiliation with or financial interest in any organization that might pose a conflict of interest. Submitted for publication: October 1, 2008; Accepted for publication: August 6, 2009.

Please direct all correspondence to: Dr. Mohammad Zia Ul Haq, Senior Resident, Central Instifute of Psychiatry, Ranchi, India-834006; Tel: 919234687231; Fax: 96512233668 ; E-mail: drziaulhaq@gmail.com. 


\section{Stahl's}

\section{Essential Psychopharmacology Masters Course}

A Curriculum-Driven Comprehensive Survey of the Field in Three Semesters

A unique educational opportunity to network with high-level colleagues and the instructor, Stephen M. Stahl, MD, PhD, author of Stahl's Essential Psychopharmacology, Third Edition! A 3-part live course featuring concepts from this latest best-seller and theoretical presentations based on treatment and outcomes from Dr. Stahl's own practice. Seven major neurotransmitter systems, seven major drug classes and ten critical concepts of psychopharmacology are reviewed.

\section{Each semester is worth up to 15.0 AMA PRA Category 1 Credits $^{\mathrm{TM}}$}

\section{REGISTER TODAY! FOR 1, 2 OR ALL 3 SEMESTERS}

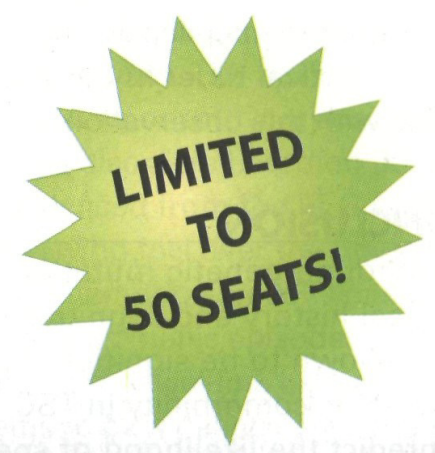

\section{Course Dates and Topics:}

July 17-19, 2009

Semester One:

Psychosis and Antipsychotics
October 9-11, 2009

Semester Two:

Mood, Pain, Antidepressants and Mood Stabilizers
January $15-17,2010$

Semester Three:

Special Topics--Anxiety, Drug Abuse, Sleep/Wake, ADHD and Dementia

\section{Registration Options:}

Phone: $+1(888) 535-5600$ 


\section{THE NEXT GENERATION OF BLACK BOOKS NOW AVAILABLE}

The Black Book of Psychotropic

Dosing and Monitoring

12th Edition
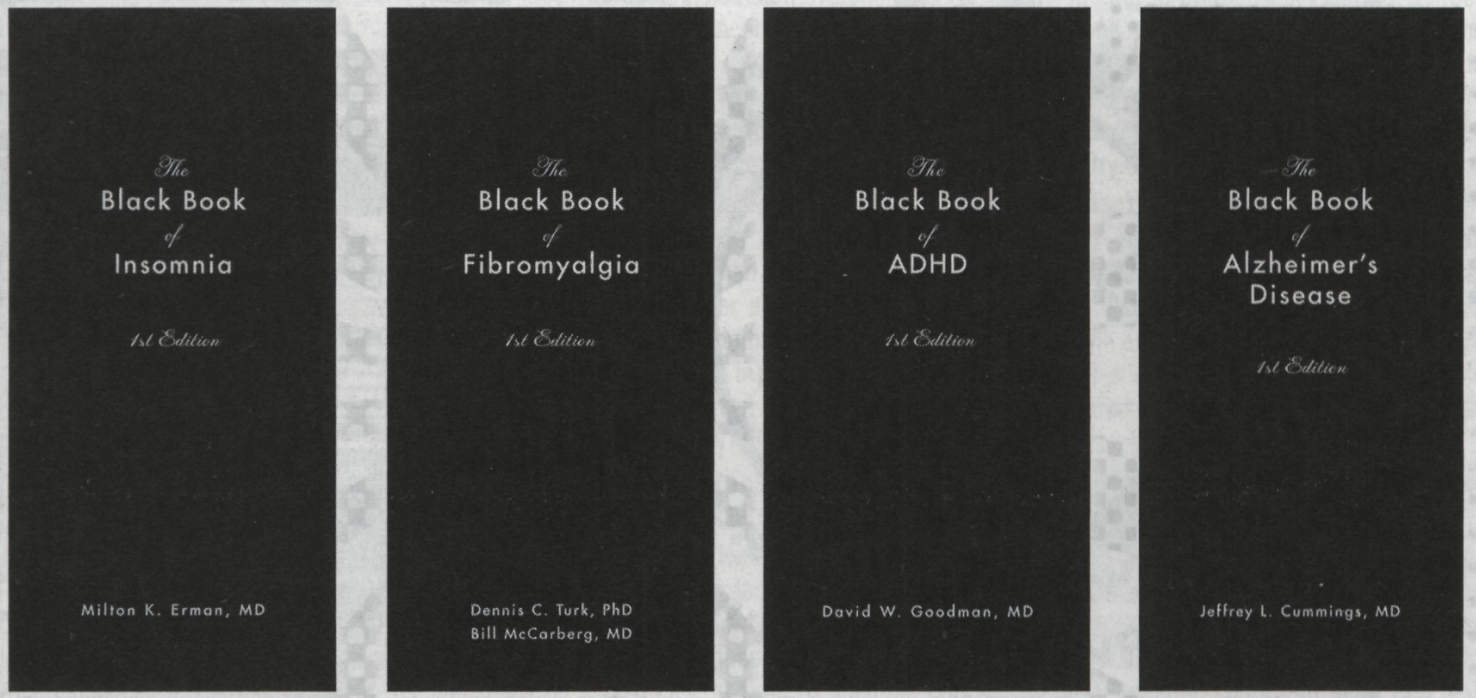

\section{ORDER YOUR BLACK BOOK COPIES ONLINE}

The Black Book of Psychotropic Dosing and Monitoring

The Black Book of Insomnia

The Black Book of Fibromyalgia

The Black Book of ADHD

The Black Book of Alzheimer's Disease

Coming Soon-The Black Book of CNS Drug Interactions

Spiral bound print versions of each Black Book are now available for only $\$ 12.99$ plus $S \& H$. *

Interactive e-versions for your desktop and/or smart phone are coming soon.

To order, please visit Customer Service at www.cnsspectrums.com

*Please allow 6-8 weeks for delivery 


\section{NO PASSWORD. NO FEF. NO HASSLE. JUST PEER-REVIEWED CLINICAL INFORMATION www.cnsspectrums.com}
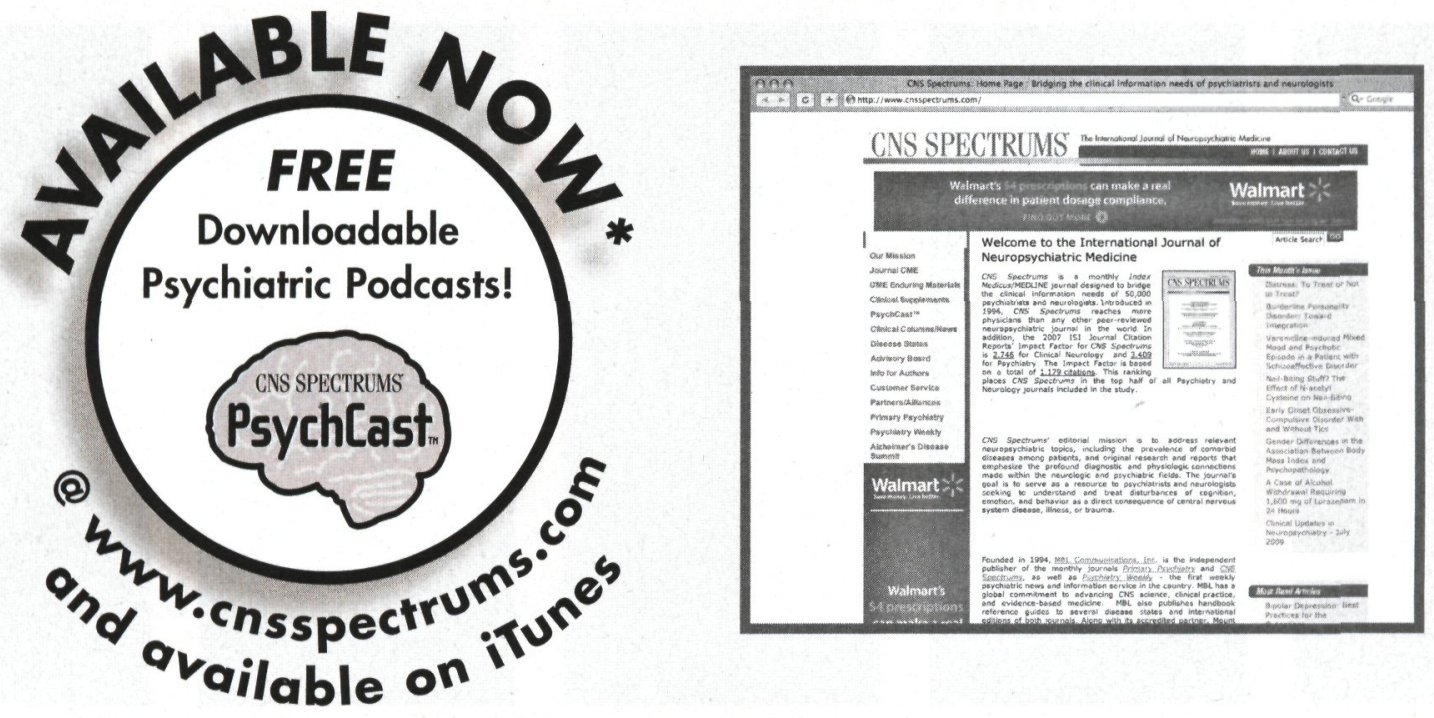

*Click on the PsychCast ${ }^{\mathrm{TM}}$ button at www.cnsspectrums.com

CNS-Based Podcast Programming from the Publishers of Primary Psychiatry, CNS Spectrums, and Psychiatry Weekly

CNS Spectrums' Web portal is now better than ever - a one-stop source providing the following integrated services based on input from you... our readers:

- eSubmissions of Manuscripts and ePeer Review via ScholarOne's Manuscript Central

- RSS Feeds for Current Issues, CME articles and Academic Supplements

- Enhanced Citation-based Article Search

- Dynamic Pop-Up Article Images

- Downloadable Article PDFs

- elearning via Enduring Materials
- Most-Read Articles automatically tabulated

- Integrated Customer Service Tools, including an Online Store featuring all Clinical Handbooks

- A host of additional services and features...including hyperlink access to MBL's other CNS sources: www.primarypsychiatry.com and www.psychiatryweekly.com

To learn more, please visit www.cnsspectrums.com or www.mblcommunications.com PRIMARY PSYCHIATRY CNS SPECTRUMS PsychiatryWeekly.

A Global Commitment to Advancing CNS Science, Clinical Practice, and Evidence-Based Medicine 
INTUNIVTM (guanfacine) Extended-Release Tablets

Rx Only

BRIEF SUMMARY: Consult the Full Prescribing Information for complete product information.

\section{INDICATIONS AND USAGE}

INTUNIVTM is indicated for the treatment of Attention Deficit Hyperactivity Disorder (ADHD). The efficacy of INTUNIVTM was studied for the treatment of ADHD in two controlled clinical trials ( 8 and 9 weeks in duration) in children and adolescents ages 6-17 who met DSM-IV ${ }^{\circledR}$ criteria for ADHD (see Clinical Studies in Full Prescribing Information). The effectiveness of INTUNIVTM for longer-term use (more than 9 weeks) has not been systematically evaluated in controlled trials.

Maintenance Treatment The effectiveness of INTUNIV ${ }^{7 M}$ for longer-term use (more than 9 weeks) has not been systematically evaluated in controlled trials. Therefore the physician electing to use INTUNIVTM for extended periods should periodically re-evaluate the long-term usefulness of the drug for the individual patient.

\section{CONTRAINDICATIONS}

Patients with a history of hypersensitivity to INTUNIVTM, its inactive ingredients (see Description in Full Prescribing information), or other products containing guanfacine (e.g. TENEX ${ }^{\circledR}$ ) should not take INTUNIVTM.

\section{WARNINGS AND PRECAUTIONS}

Hypotension, Bradycardia, and Syncope Treatment with INTUNIVTM can cause decreases in blood pressure and heart rate. In the pediatric, short-term (8-9 weeks), controlled trials, the maximum mean changes from baseline in systolic blood pressure, diastolic blood pressure, and pulse were $-5 \mathrm{~mm} \mathrm{Hg},-3 \mathrm{~mm} \mathrm{Hg}$, and $-6 \mathrm{bpm}$, respectively, for all dose groups combined (generally one week after reaching target doses of $1 \mathrm{mg} /$ day, $2 \mathrm{mg} /$ day, $3 \mathrm{mg} /$ day or $4 \mathrm{mg} /$ day). These changes were dose dependent. Decreases in blood pressure and heart rate were usually modest and asymptomatic; however, hypotension and bradycardia can occur. Hypotension was reported as an adverse event for $6 \%$ of the INTUNIVTM group and $4 \%$ of the placebo group. Orthostatic hypotension was reported for $1 \%$ of the INTUNIVTM group and none in the placebo group. In long-term, open label studies, (mean exposure of approximately 10 months), maximum decreases in systolic and diastolic blood pressure occurred in the first month of therapy. Decreases were less pronounced over time. Syncope occurred in $1 \%$ of pediatric subjects in the clinical program. The majority of these cases occurred in the long-term, open-label studies. Measure heart rate and blood pressure prior to initiation of therapy, following dose increases, and periodically while on therapy. Use INTUNIVTM with caution in patients with a history of hypotension, heart block, bradycardia, or cardiovascular disease, because it can decrease blood pressure and heart rate. Use caution in treating patients who have a history of syncope or may have a condition that predisposes them to syncope, such as hypotension, orthostatic hypotension, bradycardia, or dehydration. Use INTUNIV ${ }^{\mathrm{M}}$ with caution in patients treated concomitantly with antihypertensives or other drugs that can reduce blood pressure or heart rate or increase the risk of syncope. Advise patients to avoid becoming dehydrated or overheated.

Sedation and Somnolence Somnolence and sedation were commonly reported adverse reactions in clinical studies ( $38 \%$ for INTUNIVTM vs. $12 \%$ for placebo) in children and adolescents with ADHD, especially during initial use (see Adverse Reactions in Full Prescribing Information). Before using INTUNIV ${ }^{M}$ with other centrally active depressants (such as phenothiazines, barbiturates, or benzodiazepines), consider the potential for additive sedative effects. Caution patients against operating heavy equipment or driving until they know how they respond to treatment with INTUNIVTM. Advise patients to avoid use with alcohol.

Other Guanfacine-Containing Products Guanfacine, the active ingredient in INTUNIVTM, is also approved as an antihypertensive. Do not use INTUNIVTM in patients concomitantly taking other guanfacine-containing products (e.g., Tenex).

\section{ADVERSE REACTIONS}

Clinical Trial Experience Two short-term, placebo-controlled, double-blind pivotal studies (Studies 1 and 2) were conducted in children and adolescents with ADHD with a dose range of 1 to $4 \mathrm{mg} /$ day of INTUNIVTM. The most commonly reported adverse reactions (occurring in $\geq 2 \%$ of patients) that were considered drug-related and reported in a greater percentage of patients taking INTUNIV ${ }^{\mathrm{TM}}$ compared to patients taking placebo were: somnolence, headache, fatigue, upper abdominal pain, nausea, lethargy, dizziness, irritability, hypotension/decreased blood pressure, decreased appetite, dry mouth, and constipation. Less common adverse reactions $(<2 \%)$ reported in pivotal Studies 1 and 2 that occurred in more than one patient taking INTUNIV ${ }^{\mathrm{M}}$ and were more common than in the placebo group are atrioventricular block, bradycardia, sinus arrhythmia, dyspepsia, asthenia, chest pain, increased alanine aminotransferase, increased blood pressure, increased weight, postural dizziness, increased urinary frequency, enuresis, asthma, orthostatic hypotension, and pallor. In addition, the following less common $(<2 \%)$ psychiatric disorders occurred in more than one patient receiving INTUNIV'M and were more common than in the placebo group. The relationship to INTUNIVTM could not be determined because these events may also occur as symptoms in pediatric patients with ADHD: agitation, anxiety, depression, emotional lability, nightmares or interrupted sleep. Twelve percent (12\%) of patients receiving INTUNIVTM discontinued from the clinical studies due to adverse events, compared to $4 \%$ in the placebo group. The most common adverse reactions leading to discontinuation of INTUNIVTM-treated patients from the studies were somnolence/sedation $(6 \%)$ and fatigue ( $2 \%$ ). Less common adverse reactions leading to discontinuation (occurring in approximately $1 \%$ of patients) included: hypotension/decreased blood pressure, headache, and dizziness. In the controlled long term studies (mean duration of approximately 10 months) with a dose range of 1 to $4 \mathrm{mg} /$ day of INTUNIV ${ }^{\mathrm{TM}}$, the most common adverse reactions ( $\geq 5 \%$ ) reported during open label treatment were somnolence, headache, fatigue, upper abdominal pain, hypotension/decreased blood pressure, vomiting, dizziness, nausea, weight increased, and irritability. The most frequent adverse reactions leading to discontinuation $(\geq 2 \%)$ were somnolence $(3 \%)$, syncopal events $(2 \%)$, increased weight $(2 \%)$, depression $(2 \%)$, and fatigue $(2 \%)$. Other adverse reactions leading to discontinuation in the long-term studies (occurring in approximately $1 \%$ of patients) included: hypotension/decreased blood pressure, sedation, headache, and lethargy. In long-term open label studies, serious adverse reactions occurring in more than one patient were syncope $(2 \%)$ and convulsion $(0.4 \%$ ). Adverse reactions that occurred in $<5 \%$ of patients but $\geq 2 \%$ in open-label, long-term studies that are considered possibly related to INTUNIVTM include: syncopal events, constipation, stomach discomfort, hypertension/increased blood pressure, decreased appetite, diarrhea, dry mouth, lethargy, and insomnia.

Effects on Height, Weight, and Body Mass Index (BMI) Patients taking INTUNIV'M demonstrated similar growth compared to normative data. Patients taking INTUNIVTM had a mean increase in weight of $1 \mathrm{~kg}(2 \mathrm{lbs})$ compared to those receiving placebo over a comparative treatment period. Patients receiving INTUNIVTM for at least 12 months in open-label studies gained an average of $8 \mathrm{~kg}(17 \mathrm{lbs})$ in weight and $8 \mathrm{~cm}(3 \mathrm{in})$ in height. The height, weight, and BMI percentile remained stable in patients at 12 months in the long-term studies compared to when they began receiving INTUNIVTM.

Laboratory Tests in short and long-term studies, no clinically important effects were identified on any laboratory parameters.

Effects on Heart Rate and QT Interval The effect of two dose levels of immediaterelease guanfacine ( $4 \mathrm{mg}$ and $8 \mathrm{mg}$ ) on the QT interval was evaluated in a doubleblind, randomized, placebo- and active-controlled, cross-over study in healthy adults. A dose-dependent decrease in heart rate was observed during the first 12 hours, at time of maximal concentrations. The mean change in heart rate was $-13 \mathrm{bpm}$ at $4 \mathrm{mg}$ and $-22 \mathrm{bpm}$ at $8 \mathrm{mg}$. An apparent increase in mean QTc was observed for both doses. However, guanfacine does not appear to interfere with cardiac repolarization of the form associated with pro-arrhythmic drugs. This finding has no known clinical relevance.

\section{USE IN SPECIFIC POPULATIONS}

Pregnancy: Pregnancy Category B. There are no adequate and well-controlled studies of guanfacine in pregnant women. This drug should be used during pregnancy only if clearly needed.

Nursing Mothers: It is not known whether guanfacine is excreted in human milk. Because many drugs are excreted in human milk, caution should be exercised when INTUNIVTM is administered to a nursing woman.

Pediatric Use: The safety and efficacy of INTUNIVTM in pediatric patients less than 6 years of age have not been established.

Geriatric Use: The safety and efficacy of INTUNIV'M in geriatric patients have not been established.

\section{DRUG ABUSE AND DEPENDENCE}

INTUNIVTM is not a controlled substance and has no known potential for abuse or dependence.

\section{OVERDOSAGE}

Two cases of accidental overdose of INTUNIVTM were reported in clinical trials in pediatric ADHD patients. These reports included adverse reactions of sedation and bradycardia in one patient and somnolence and dizziness in the other patient. Consult with a Certified Poison Control Center for up to date guidance and advice.

Manufactured for Shire US Inc., Wayne, PA 19087.

INTUNIVTM is a trademark of Shire LLC.

(C) 2009 Shire Pharmaceuticals Inc.

August $2009 \quad 5130207001 \quad$ INT-00239 